\title{
Transmission of Scrapie by Steel-surface-bound Prions
}

\author{
Eckhard Flechsig, ${ }^{1 *}$ Ivan Hegyi, ${ }^{2 *}$ Masato Enari, ${ }^{1}$ Petra Schwarz, ${ }^{2}$ John Collinge, ${ }^{1}$ \\ and Charles Weissmann ${ }^{1}$ \\ ${ }^{1}$ MRC Prion Unit and Department of Neurogenetics, Imperial College School of Medicine at St. Mary's, \\ London, U.K. \\ ${ }^{2}$ Institut für Neuropathologie, Universitätsspital Zürich, Zürich, Switzerland \\ Communicated by C. Weissmann. Accepted August 27, 2001
}

\begin{abstract}
Background: Prions are unusually resistant to conventional disinfection procedures. An electrode used intracerebrally on a Creutzfeldt-Jakob disease (CJD) patient transmitted the disease to two patients in succession and finally to a chimpanzee, despite attempted disinfection. Concerns that surgical instruments may transmit variant CJD have been raised by the finding of $\operatorname{PrP}^{\mathrm{Sc}}$, a surrogate marker for infectivity, in various tissues other than brain. Materials and Methods: Stainless steel wire was exposed to scrapie-infected brain or brain homogenate, washed exhaustively and inserted into the brain of indicator mice to measure infectivity.

Results: A contact time of 5 min with scrapie-infected mouse brain suffices to render steel wire highly infectious and insertion of infectious wire into the brain of an
\end{abstract}

\section{Introduction}

Prions are more resistant to inactivation than most conventional pathogens (1-4). An electrode used intracerebrally on a patient suffering from sporadic CJD (sCJD) transmitted the disease to two patients in succession and finally to a chimpanzee, despite exposure to benzene, $70 \%$ ethanol and formaldehyde vapour after each use $(5,6)$. Concerns that surgical instruments may transmit variant CreutzfeldtJakob disease (vCJD) have been raised by the finding of $\mathrm{PrP}^{\mathrm{Sc}}$ not only in nervous, but also in lymphatic tissue (7-10). We examined the ability of steel surfaces to bind scrapie prions by incubating steel wires overnight with scrapie-infected brain homogenates and inserting them permanently into the brain of indicator mice. This procedure resulted in efficient transmission of disease (11).

However, long-time exposure of steel wires to brain homogenate does not reflect conditions obtaining during surgical interventions. We now show that wires inserted into intact brain for as little as 5 min suffices to render the wires far more infectious than overnight

Address correspondence and reprint requests: Charles Weissmann, MCR Prion Unit and Department of Neurogenetics, Imperial College School of Medicine at St. Mary's, London W2 1 PG, U.K. E-mail: c.weissmann@ic.ac.uk.

*These authors contributed equally to this work. indicator mouse for 30 min suffices to cause disease. Infectivity bound to wires persists far longer in the brain than when injected as homogenate, which can explain the extraordinary efficiency of wire-mediated infection. No detectable amounts of PrP could be eluted with $\mathrm{NaOH}$, however the presence of PrP on infectious wires was demonstrated by chemiluminescence. Several recommended sterilisation procedures inactivated wire-bound mouse prions, but exposure to $10 \%$ formaldehyde was insufficient.

Conclusions: Prions are readily and tightly bound to stainless steel surfaces and can transmit scrapie to recipient mice after short exposure times. This system mimics contaminated surgical instruments and will allow an assessment of sterilisation procedures. exposure to brain homogenate and as infectious as $0.03 \mathrm{ml}$ of $1 \%$ scrapie-infected brain homogenate injected directly into the brain. Furthermore, a contact time of 30 min was sufficient to elicit infection. Our experiments provide a model to assess the effectiveness of sterilisation procedures for steel bound prions and suggest a minimally invasive approach to assess infectivity in organs such as brain and tonsils.

\section{Materials and Methods \\ Preparation of Infectious Wire}

Stainless steel wire segments (diameter $0.15 \mathrm{~mm}$; $5 \mathrm{~mm}$ length) were cut from "Stainless steel suture monofilament wire", Art.Nr. 01614037, USP 4/0, B.Braun Melsungen AG, D-34209 Melsungen, Germany; batch 1/7502 or 1/8452). Gold wire segments $(5 \times 0.13 \mathrm{~mm}$, Alfa Aesar Johnson Matthey GmbH Germany) were washed ultrasonically for $15 \mathrm{~min}$ in $2 \%$ Triton $\mathrm{X}-100$, thoroughly rinsed in distilled water, dried at $37^{\circ} \mathrm{C}$ for $1 \mathrm{~h}$ as described (12). Brains were homogenized in $1 \times$ Dulbecco's phosphate-buffer saline (D-PBS; Gibco BRL, Glasgow, UK) by passing through $21 \mathrm{G}$ and $25 \mathrm{G}$ needles 8 times each, to give $10 \%(\mathrm{w} / \mathrm{v})$ homogenates. These were centrifuged at 1,000 rpm (Eppendorf centrifuge 5415c, Hamburg, Germany) for $5 \mathrm{~min}$ at room temperature and the supernatants were recovered. We have recently determined that the centrifugation step result 
in the precipitation of about $80-90 \%$ of the $\mathrm{PrP}^{\mathrm{Sc}}$ present in the sample (P. Klöhn, unpublished results) so that this step is better avoided. Wires were incubated with centrifuged $10 \%$ brain homogenate in PBS for $16 \mathrm{~h}$ and washed 5 times $10 \mathrm{~min}$ in $50 \mathrm{ml}$ PBS, all at room temperature. The wires were air-dried, stored at room temperature for 1 day and inserted into brain of deeply anaesthetized indicator mice, using a 25 -gauge injection needle as a trocar.

\section{Chemiluminescence of Surface-bound PrP}

Twenty stainless wire segments $(0.15 \times 5 \mathrm{~mm})$ were inserted into one brain hemisphere for 5 minutes. The other hemisphere was homogenized and centrifuged as described above. Twenty stainless wire segments were incubated with $0.5 \mathrm{ml} 10 \%$ centrifuged homogenate for 5 min at room temperature, washed five times for 10 min with $50 \mathrm{ml}$ D-PBS, dried for $24 \mathrm{~h}$ and immediately assayed for PrP. Wires were incubated with $0.2 \mathrm{ml}$ of D-PBS containing $5 \%$ non-fat dry milk (w/v; Marvel, Premier Brands UK Ltd., Wirral, Merseyside, U.K.) for $1 \mathrm{~h}$ with agitation. After removal of the blocking reagent, they were incubated for $1 \mathrm{~h}$ with $200 \mathrm{ng} / \mathrm{ml}$ of anti-PrP antibody (6H4; Prionics AG, Zürich, Switzerland) in D-PBS containing $1 \%$ non-fat dry milk and washed 3 times for $5 \mathrm{~min}$ with $0.2 \mathrm{ml}$ of D-PBS, followed by incubation for $1 \mathrm{~h}$ with horseradish peroxidase-conjugated rabbit antimouse IgGl (1: 5000 dilution; Zymed, South San Francisco, California, USA). After washing 5 times for 5 min with D-PBS, the wires were exposed to $0.2 \mathrm{ml}$ of SuperSignal ELISA Femto Maximum Sensitivity Substrate (Pierce, Rockford, ILL, USA) according to the manufacturer's instructions. Chemiluminescence was determined by luminometer (AutoLumat LB953; EGEG Berthold GmbH, Bad Wildbad, Germany).

\section{Results}

The ability of stainless steel surfaces to bind scrapie infectivity has been previously demonstrated by incubating steel wires $(5 \times 0.15 \mathrm{~mm})$ for $16 \mathrm{~h}$ with $10 \%$ w/v brain homogenate of terminally scrapie-sick mice, referred to below as "standard conditions" (11). To model the exposure of surgical instruments to infected tissue more realistically, we inserted wire segments for 5, 30 or 120 min into brains of scrapieinoculated wild-type mice culled two months before the expected appearance of scrapie symptoms. These "transiently inserted" wires were washed, dried and assayed by permanent implantation into the brain of Tga 20 indicator mice (13). Incubation times of the three groups lay between $65 \pm 4$ and $69 \pm 5$ days (Table 1, experiment 1), showing that even the shortest exposure to scrapie-infected brain rendered wires as infectious as intracerebral inoculation with $0.03 \mathrm{ml}$ of $1 \%$ homogenate of the same brain homogenate (incubation time of $68 \pm 8$ days). Gold wires exposed to brain homogenate into brain also acquired infectivity (Table 1, experiment 2 ).

A second important question regards the length of time an infectious wire must contact brain tissue in order to initiate disease. Infectious wires were

\section{Table 1. Infectivity of steel or gold wires after exposure to intact brain or to brain homogenate} of scrapie-infected mice

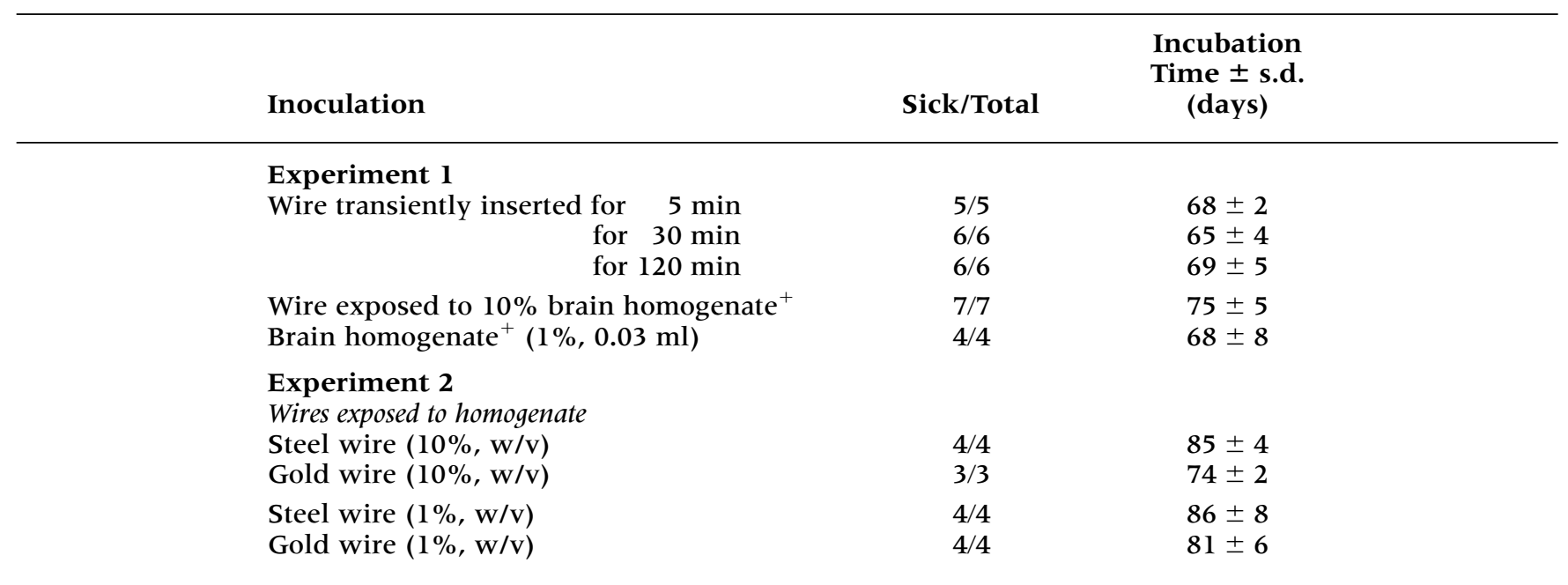

For experiment 1 , two C57BL/6 mice were culled 87 days after i.c. inoculation with RML, that is, about 2 months before appearance of clinical symptoms. Wires were inserted into brain for the time indicated or exposed to centrifuged $10 \%$ brain homogenate for $16 \mathrm{~h}$ and processed as described in the Methods section. For experiment 2, wire segments were exposed to centrifuged brain homogenate of RML-infected, terminally sick CD 1 mice as described in Methods.

${ }^{+} 6.8 \log \mathrm{LD}_{50}$ units/ml 10\% homogenate, as determined by end point titration (23) in Tga 20 mice. 
Table 2. Transient insertion of infectious wires into brains of indicator mice

\begin{tabular}{|c|c|c|}
\hline Inoculation & Sick/Total & $\begin{array}{l}\text { Incubation } \\
\text { Time } \pm \text { s.d. } \\
\quad \text { (days) }\end{array}$ \\
\hline $\begin{array}{l}\text { Wires infected by exposure to scrapie brain } \\
\text { (a) Transient insertion into indicator mice } \\
\quad 30 \mathrm{~min} \\
120 \mathrm{~min}\end{array}$ & $\begin{array}{l}4 / 4^{\$} \\
2 / 2^{\#}\end{array}$ & $\begin{array}{c}94 \pm 10 \\
100 \pm 18^{\delta}\end{array}$ \\
\hline $\begin{array}{l}\text { (b) Permanent insertion into indicator mice } \\
\text { Wires not previously inserted } \\
\text { Wires after transient insertion for: } \\
30 \mathrm{~min} \\
120 \mathrm{~min}\end{array}$ & $\begin{array}{l}3 / 3 \\
4 / 4 \\
5 / 5\end{array}$ & $\begin{array}{l}71 \pm 2 \\
71 \pm 3 \\
68 \pm 1\end{array}$ \\
\hline $\begin{array}{l}\text { (c) Controls } \\
\text { Wires exposed to brain homogenate } \\
\text { Brain homogenate }(1 \%, 0.03 \mathrm{ml})\end{array}$ & $\begin{array}{l}6 / 6 \\
3 / 3\end{array}$ & $\begin{array}{l}76 \pm 3 \\
69 \pm 3\end{array}$ \\
\hline $\begin{array}{l}\text { Infectious wires were prepared by insertion for } 5 \text { min into the brain of C } \\
\text { RML and washed with } 50 \mathrm{ml} \text { PBS } 5 \text { times for } 10 \text { min. Infectious wires } \mathrm{w} \\
\text { indicator mice for the times indicated. The recovered wires were washed } \\
\text { controls, wires incubated with centrifuged } 10 \% \text { homogenate }(6.8 \log \mathrm{LD} 5 \\
\text { introduced into indicator mice. } \\
{ }^{\$} \text { Two of } 6 \text { mice died on the day of the intervention. } \\
\text { \#Four of } 6 \text { mice died within a day of the intervention. } \\
\text { F Incubation times were } 87 \text { and } 113 \text { days. }\end{array}$ & $\begin{array}{l}\text { 129Sv mice c } \\
\text { nted into brair } \\
\mathrm{ml} \text { PBS and in } \\
\mathrm{ml} \text { ) of the san }\end{array}$ & $\begin{array}{l}1 \text { days after i } \\
\text { eeply anaesth } \\
\text { into Tga } 20 \text { is } \\
\text { and the hom }\end{array}$ \\
\hline
\end{tabular}

prepared by insertion for 5 min into the brain of an infected wild-type mouse culled one month before the expected onset of scrapie symptoms. After washing, the wires were inserted transiently into the brains of anaesthetised indicator mice. As shown in Table 2, all mice exposed to a wire for $30 \mathrm{~min}$ or $2 \mathrm{~h}$ developed symptoms after $94 \pm 10$ and $100 \pm 18$ days, respectively. The infectious wires, with or without subsequent exposure to brain tissue, were ultimately assayed in indicator mice and in all cases caused scrapie disease after about 70 days, showing that no detectable amounts of infectivity were lost by exposure to brain.

Earlier experiments had shown that no detectable protein could be eluted with $2 \mathrm{M} \mathrm{NaOH} \mathrm{(<50} \mathrm{ng} \mathrm{pro-}$ tein per wire) from wires exposed to $10 \%$ brain homogenate (11). To determine whether wires exposed to brain homogenate or to intact brain had surface-bound PrP, they were incubated with monoclonal PrP antibody 6H4 (14), followed by horseradish peroxidase-conjugated rabbit anti mouse IgGl and chemiluminescence was measured in the presence of substrate. Fig. 1 shows that chemiluminescence of wires transiently inserted into infected brain of terminally sick indicator mice was about 5.5 times above reagent background. After background subtraction, the values were about 4 times higher than for wires exposed to infected brain homogenate and about 1.8 times higher than for those transiently inserted into uninfected brain. This experiment shows that PrP was bound to the wire surface; the higher

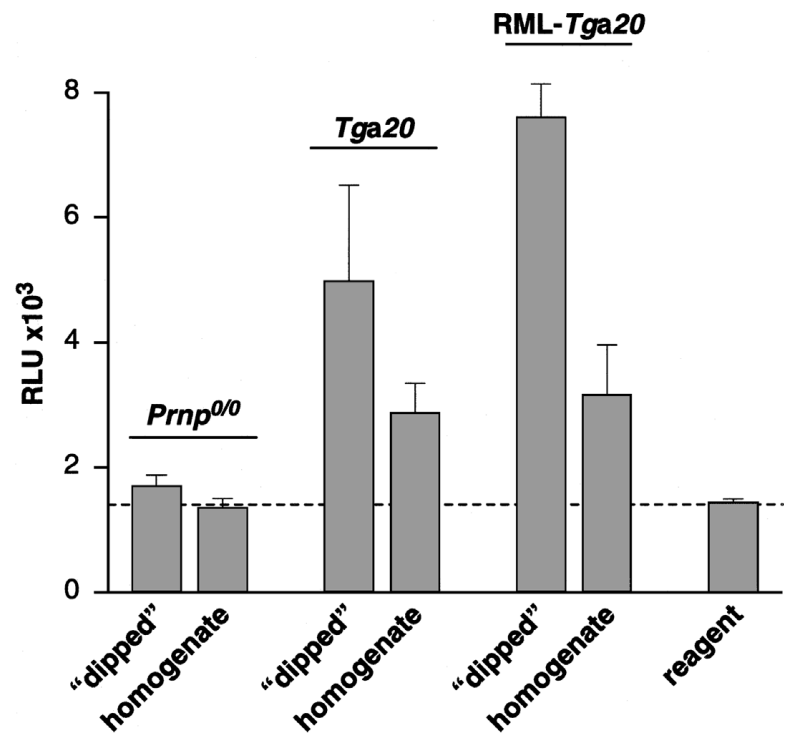

Fig. 1. Chemiluminescence of surface-bound PrP on stainless steel wires exposed to brain or brain homogenates. Stainless steel wire segments were transiently inserted into brains ("dipped") or incubated with $10 \%$ brain homogenates (homogenate) from PrP knockout mice $\left(\operatorname{Prnp}^{0 / 0}\right)$, uninfected (Tga20) and RML-infected, terminally sick Tga20 mice (RMLTga20). Wires were washed, treated with anti-PrP antibody $6 \mathrm{H} 4$ and horseradish peroxidase-conjugated anti-mouse IgGl antibody, and chemiluminescence was determined. The dotted line indicates the background level, given by reagents alone (reagent). Averages and standard deviations were calculated from three samples each. RLU, relative light units. 
chemiluminescence of the sample from infected brain is in keeping with the finding that total PrP content in terminally infected mouse brain is around 5 times higher than in uninfected controls $(13,15)$, due to accumulation of $\operatorname{PrP}^{\mathrm{Sc}}$. We were not able to differentiate between $\operatorname{PrP}^{\mathrm{C}}$ and $\operatorname{PrP}^{\mathrm{Sc}}$ on wires because proteinase $\mathrm{K}$ treatment abolished immunofluorescence in all cases (data not shown). In an attempt to desorb PrP, we extracted 40 wire segments that had been transiently inserted into scrapie-infected brain with $0.05 \mathrm{ml} 2 \mathrm{M}$ $\mathrm{NaOH}$ for $1 \mathrm{~h}$, neutralised the eluate with $\mathrm{HCl}$ and analysed half the sample by Western blot analysis. No PrP-specific immunoreactivity was detected under conditions where $0.3 \mathrm{ng}$ purified glycosylated murine $\mathrm{PrP}$, dissolved in $\mathrm{NaOH}$ and neutralised as described above, was clearly detectable (data not shown). Therefore, one wire released less than $15 \mathrm{pg} \operatorname{PrP}$, that is less than $3 \times 10^{8}$ molecules. Assuming that one $\log L D_{50}$ unit of infectivity is associated with $10^{5} \mathrm{PrP}^{\mathrm{Sc}}$ molecules
(16), one wire released less than $3000 \mathrm{LD}_{50}$ units. Yet, the incubation time resulting from one wire is about the same as that following injection of $0.03 \mathrm{ml}$ $1 \%$ brain homogenate, which corresponds to about $20^{\prime} 000 \mathrm{LD}_{50}$ units. This somewhat speculative calculation suggests that the amount of PrP that could have been released from the wire surface does not readily account for the wire's infectivity, raising the question whether infectivity is due to irreversibly bound $\operatorname{Pr} \mathrm{P}^{\mathrm{Sc}}$ (or PrP*) (17) rather than to desorbed prions.

Why are wire-bound prions as infectious as concentrated homogenates? Upon intracerebral inoculation with brain homogenate, infectivity is rapidly distributed throughout the mouse (18) and after 4 days or less prions are no longer detectable in the brain (19). Perhaps wire-bound prions are more stable and can therefore act over a longer period of time. We assayed infectious wires directly or after leaving them for 1 or 5 days in brains of Prnp ${ }^{+/+}$or Prnp ${ }^{0 / 0}$ mice. Table 3.

Table 3. Infectivity of prion-coated wire after exposure to brain homogenate, PBS or brain of uninfected mice

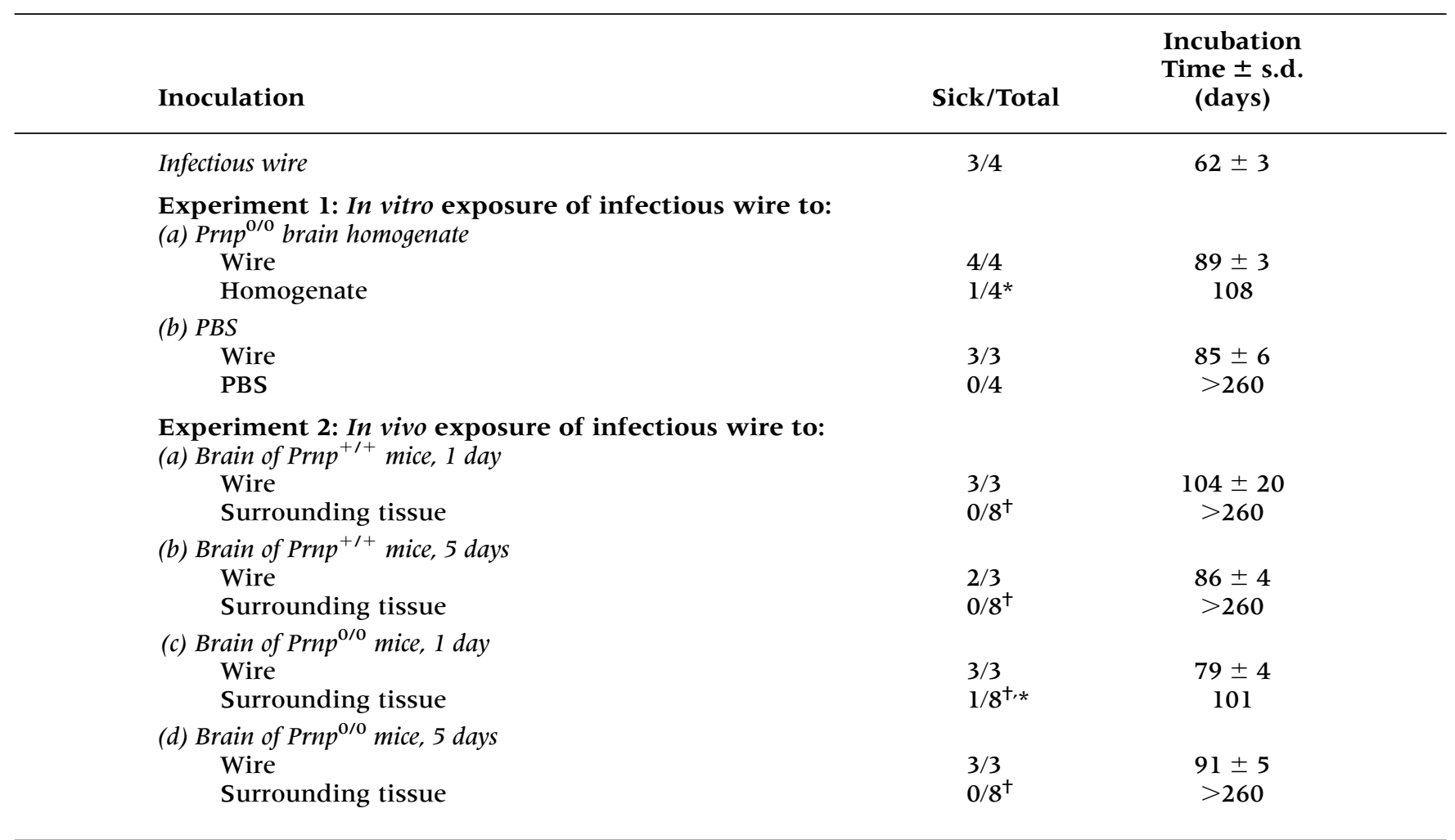

Infectious wires were prepared with centrifuged $10 \%$ brain homogenate from terminally sick CD 1 mice (11). For the in vitro assay (expt.1), 20 wires were shaken in Eppendorf tubes for $24 \mathrm{~h}$ at $37^{\circ} \mathrm{C}$, either with $0.2 \mathrm{ml}$ freshly prepared brain homogenate $(10 \%$ w/v in PBS) of uninfected Prnp ${ }^{0 / 0}$ mice or with $0.2 \mathrm{ml} \mathrm{PBS} / 0.1 \%$ albumin, on a thermomixer (1400 rpm). After washing with $0.2 \mathrm{ml}$ of the cognate solution, wires were assayed for infectivity. Thirty- $\mu \mathrm{l}$ samples of each preparation $(0.4 \mathrm{ml})$ were assayed for infectivity in $\mathrm{Tga} 20$ indicator mice. For the in vivo experiment (expt.2), infectious wires were implanted into the brain of uninfected Prnp ${ }^{+/+}$(C57Bl6) or Prnp ${ }^{0 / 0}$ mice. After 1 and 5 days, respectively, the mice were culled and the brain tissue immediately surrounding the wire was dissected out. Wires were washed in $1 \mathrm{ml}$ PBS and assayed. The brain samples (each about $80 \mathrm{mg}$ ) were homogenised in PBS to give a $10 \%$ homogenate and centrifuged samples were injected i.c. into 3 indicator mice each.

*Scrapie diagnosis was confirmed by histopathology or histoblotting (24)

${ }^{\dagger}$ One of 9 mice died during or after injection. 
Table 4. Infectivity of surface-bound mouse prions after various treatments

\begin{tabular}{|c|c|c|}
\hline Inoculation & Sick/Total & $\begin{array}{c}\text { Incubation } \\
\text { Time } \pm \text { s.d. } \\
\quad \text { (days) }\end{array}$ \\
\hline \multicolumn{3}{|l|}{ 1. Uninfected wires } \\
\hline Untreated & $0 / 3$ & $>260$ \\
\hline \multicolumn{3}{|l|}{ 2. Infectious wires } \\
\hline Untreated & $6 / 6$ & $76 \pm 5$ \\
\hline Sodium hydroxide $\left(1 \mathrm{M}, 1 \mathrm{~h}, 25^{\circ} \mathrm{C}\right)$ & $0 / 6$ & $>260$ \\
\hline Formaldehyde $\left(10 \%, 1 \mathrm{~h}, 25^{\circ} \mathrm{C}\right)$ & $6 / 6$ & $92 \pm 8$ \\
\hline Guanidinium thiocyanate $\left(4 \mathrm{M}, 16 \mathrm{~h}, 25^{\circ} \mathrm{C}\right)$ & $0 / 6$ & $>260$ \\
\hline
\end{tabular}

Infectious wires were prepared with centrifuged brain homogenates and assayed as described (11). End point titration (23) of the homogenate gave a titre of $6.75 \mathrm{log}$ LD50 units $/ \mathrm{ml} 10 \%$ homogenate. $\mathrm{NaOH}$ and formaldehyde solutions were prepared immediately prior to use; 4 M guanidinium thiocyanate was RNA Lysis buffer (\#40082, Applied Biosystems, Foster City, CA, USA). Wires were exposed to $1 \mathrm{ml}$ solution and washed with $1 \mathrm{ml}$ PBS four times prior to implantation.

shows that wires remained infectious even after residing in brain tissue for 5 days, albeit at a lower level, as evidenced by incubation times of about 90 days in indicator mice. Because wire-bound infectivity remains at a locally high concentration for 5 days or longer, it may result in a greater total exposure than injected homogenate.

The wire model will ultimately serve as model for the sterilisation of surgical instruments by recommended $(1,3,20)$ or novel procedures. In a preliminary experiment, infectious wire segments were subjected to different treatments and assayed. Sodium hydroxide ( $1 \mathrm{M}, \mathrm{l} \mathrm{h}$ ) or guanidinium thiocyanate $(4 \mathrm{M}, 16 \mathrm{~h})$ rendered the wires completely non-infectious to the limits of the bioassay (Table 4), however all 6 indicator mice challenged with formaldehyde-treated, prion-coated wires succumbed to scrapie after $92 \pm 8$ days.

These preliminary decontamination studies should not be extrapolated to the level of instruments used in surgery. First, we used RML mouse prions, a mouse-adapted scrapie isolate (21) which is less heat stable than mouse-passaged BSE (301V) or the hamster strain $263 \mathrm{~K}(3,22)$. It is clearly necessary to conduct sterilisation experiments of surfacebound infectivity using CJD, vCJD and BSE prions in an appropriately sensitive host. Second, the area of contact between wire surface and tissue is very small, compared with that of surgical instruments and it will ultimately be necessary to use scaled-up surfaces, such as could be provided by small steel beads introduced into larger indicator animals, to validate results obtained in the mouse.

Finally, it may become possible to use wires "dipped" for short times into brain or tonsils instead of biopsied tissue to determine the presence of $\operatorname{PrP}^{\mathrm{Sc}}$ by chemiluminescence or infectivity in an appropriate indicator mouse or susceptible cultured cell line.

\section{Acknowledgements}

We thank Dr. Adriano Aguzzi for his constant support and advice, and Mr. Rob Bond and Mr. Joseph Ecsödi for help with the animal work. This work was funded by the UK Department of Health and the Medical Research Council.

\section{References}

1. Ernst DR, Race RE. (1993) Comparative analysis of scrapie agent inactivation methods. J. Virol. Methods 41(2): 193-201.

2. Taylor DM, Fraser H, McConnell I, et al. (1994) Decontamination studies with the agents of bovine spongiform encephalopathy and scrapie. Arch. Virol. 139(3-4): 313-326.

3. Taylor DM. (2000) Inactivation of transmissible degenerative encephalopathy agents: A review. Vet. J. 159(1):10-17.

4. Brown P, Gibbs CJ Jr, Amyx HL, et al. (1982) Chemical disinfection of Creutzfeldt-Jakob disease virus. N. Engl. J. Med. 306(21): 1279-1282.

5. Bernoulli C, Siegfried J, Baumgartner G, et al. (1977) Danger of accidental person-to-person transmission of CreutzfeldtJakob disease by surgery. Lancet 1(8009): 478-479.

6. Gibbs CJ Jr, Asher DM, Kobrine A, et al. (1994) Transmission of Creutzfeldt-Jakob disease to a chimpanzee by electrodes contaminated during neurosurgery. J. Neurol. Neurosurg. Psychiatry 57(6): 757-758.

7. Hill AF, Zeidler M, Ironside J, Collinge J. (1997) Diagnosis of new variant Creutzfeldt-Jakob disease by tonsil biopsy. Lancet 349(9045): 99-100.

8. Hill AF, Desbruslais M, Joiner S, et al. (1997) The same prion strain causes VCJD and BASE. Nature 389(6650): 448-450.

9. Hill AF, Butterworth RJ, Joiner S. (1999) Investigation of variant Creutzfeldt-Jakob disease and other huma prion diseases with tonsil biopsy samples. Lancet 353(9148): 183-189.

10. Wadsworth JD, Joiner S, Hill AF, et al. (2001) Tissue distribution of protease resistant prion protein in variant CreutzfeldtJakob disease using a highly sensitive immunoblotting assay. Lancet 358(9277): 164-165.

11. Zobeley E, Flechsig E, Cozzio A, et al. (1999) Infectivity of scrapie prions bound to a stainless steel surface. Mol. Med. 5(4): 240-243.

12. Williams RL, Williams DF. (1988) Albumin adsorption on metal surfaces. Biomaterials 9(3): 206-212.

13. Fischer M, Rülicke T, Raeber A, et al. (1996) Prion protein (PrP) with aminoproximal deletions restoring susceptibility 
of PrP knockout mice to scrapie. EMBO J. 15(6): 12551264.

14. Korth C, Stierli B, Streit P, et al. (1997) Prion ( $\left.\mathrm{PrP}^{\mathrm{Sc}}\right)$-specific epitope defined by a monoclonal antibody. Nature 390(6655): 74-77.

15. Büeler H, Raeber A, Sailer A, Fischer M, Aguzzi A, and Weissmann C. (1994) High prion and PrP $^{\text {Sc }}$ levels but delayed onset of disease in scrapie-inoculated mice heterozygous for a disrupted PrP gene Mol. Med. 1(1): 19-30.

16. Bolton DC, Rudelli RD, Currie JR, Bendheim PE. (1991) Copurification of Sp33-37 and scrapie agent from hamster brain prior to detectable histopathology and clinical disease. J. Gen. Virol. 72(Pt 12): 2905-2913.

17. Weissmann C. (1991) Spongiform encephalopathies. The prion's progress. Nature 349(6310): 569-571.
18. Millson GC, Kimberlin RH, Manning EJ, Collis SC. (1979) Early distribution of radioactive liposomes and scrapie infectivity in mouse tissues following administration by different routes. Vet. Microbiol. 1979, 89-99.

19. Büeler H, Aguzzi A, Sailer A, et al. (1993) Mice devoid of PrP are resistant to scrapie. Cell 73(7): 1339-1347.

20. Manuelidis L. (1997) Decontamination of Creutzfeldt-Jakob disease and other transmissible agents. J. Neurovirol. 3(1): 62-65.

21. Chandler RL. (1961) Encephalopathy in mice produced by inoculation with scrapie brain material. Lancet 1:13781379.

22. Taylor DM, Fernie K, McConnell I, Steele PJ. (1998) Observations on thermostable subpopulations of the unconventional agents that cause transmissible degenerative encephalopathies. Vet. Microbiol. 64(1): 33-38. 